\title{
Exploring the Relationship between Risk Management and Business Strategies in the Sports Goods Industry in the City of Sialkot in Pakistan
}

\section{Shah Khalid}

\author{
The London Academy of Culinary Arts and Health Care, \\ United Kingdom
}

\begin{abstract}
The purpose of this study is to explore the current state of risk management practice and the influences on it, particularly concerning competitive positioning, in the sports goods industry in the city of Sialkot, Pakistan. This study is based on the analysis of twenty semi-structured interviews. It was conducted with the owners and other key decision makers of sports goods SMEs in Sialkot. The findings indicate that the main obstacle faced in improving risk management practices relates to underestimation of their link to competitive strategising while determining the long-term strategic options. The value of this study lies in its potential to highlight the competitive situation of Pakistani SMEs within the sports goods industry in the face of increasing competition on the international scale. This study identifies the mutual impact of various types of risks, such as financial risk, reputational risk, strategic risk and price fluctuation risk, on adoption of a particular competitive strategy by SMEs. Altogether, it raises SMEs' awareness of various business scenarios which would allow them to recognise risks earlier and improve their competitive standing.
\end{abstract}

Keywords: Risk Management; Competitive Strategy; Sports Goods Industry 


\section{Introduction}

Firms use a variety of sources and resources to obtain competitive advantage and improved performance in quite dynamic marketplaces. Small and medium enterprises (SMEs) are more likely to face challenges due to lack of resources and financial limitations. As a result, in order to compete in markets and establish a solid competitive position, SMEs must develop diverse strategies and policies for seeking out less risky ways of conducting their business operations. Risk management, however, tends to be largely ignored by SMEs due to lack of the required resources and expertise, especially in emerging economies.

Pakistani SMEs face higher risks than larger firms when competing in an increasingly globalised and volatile competitive business environment. For most Pakistani SMEs, the primary concern is with economic survival (Awan et al., 2019). Owners and managers of Pakistani SMEs do not seem sufficiently knowledgeable about assessing risk factors that influence their adopted competitive strategies. They do not actively engage in prioritising risk factors according to risk impact and probability assessments. This tendency results in pursuance of inefficient control actions to manage the perceived risks, so that in the event of any of these risks materialising, these small companies can face quite negative consequences. This situation is reflected in a noticeable decline in the number of Pakistani SMEs in the sports goods industry (Awan et al., 2019; Lund-Thomsen, 2013; SMEDA, 2021). Therefore, this study attempts to identify essential components of effective risk management strategies in small and medium enterprises in Pakistan and to evaluate their successful application in order to strengthen their overall competitiveness.

The sports goods industry is one of Pakistan's major foreign exchange earners. Approximately $98 \%$ of Pakistani sports goods are sold internationally (SMEDA 2021), and most of them are exported to internationally branded sports buyers such as Nike and Adidas (Lund-Thomsen, 2013). Because these products are designed for export, they are created to meet the quality standards of internationally targeted markets. As one of the International Organization for Standardization (ISO) registered countries, Pakistan needs to activate a process of implementation of ISO standards (Awan and Ishaq Bhatti, 2003). High-quality sporting products are the outcome of a well-thought-out manufacturing process that begins with the acquisition of raw materials and ends with delivery to customers. This procedure entails the selection of high-quality raw materials, manufacture, and delivery to the customer on time.

According to the Small and Medium Enterprises Development Authority (SMEDA, (2021), the Pakistani sports goods industry consists of around approximately 6,000 SMEs, and $95 \%$ of the total sports goods production comes from the city of Sialkot. For more than 100 years, Sialkot has been an industrial hub for the production of high-quality sports goods. Awan et al. (2019) estimated that the industrial sector of Sialkot contributes to $6 \%$ of Pakistan's total exports. However, the number of registered sports goods manufacturers and exporters has declined significantly over the last decade due to competition from large-scale, heavily mechanised suppliers in China (Lund-Thomsen, 2013).

International Journal of Management and Applied Research, 2021, Vol. 8, No. 4 
This study looks at the extent to which the chosen competitive strategy would enable small firms in the sports goods industry in Sialkot to achieve a better fit with the continuously changing business environment in the context of managing risks.

\section{Literature Review}

\subsection{Risk \& Uncertainty Concepts}

Despite the multitude of studies in the areas of risks and risk management, a unanimously accepted definition of risk has been lacking (Holton, 2004). Miller (1992) perceives risk as a "performance variance" that explains an unpredictable deviation of consequences. Other management scholars suggest that the term 'risk' is mainly perceived as an undesirable and unfavourable event which needs to be mitigated or avoided (Bowers and Khorakian, 2014; Teece et al., 2016; Ward and Chapman, 2003). Olsson (2007), on the other hand, suggested seeing risk as an implicit opportunity that can lead to improvements in terms of processes or resource management.

Such diverse views on risks and their management may lead to a perception of the negative nature of risk and its association with adverse events that have not yet happened. However, in principle, the term 'risk' includes quantifiable or measurable uncertainty which can result in either positive or negative outcomes (Holton, 2004; Olsson, 2007). In addition, 'risk' relates to the concept of exposure, and could be described as an exposure to an uncertain event or a set of circumstances associated with future business conditions or environment.

In business operations, risk can originate from many different elements, and depends on a variety of events or actions while creating value for the customers. Additionally, the conditions for risks to arise can change from favourable to unfavourable or vice versa and transform risks into potential threats or opportunities (Olsson, 2007). Risks are not of an 'on-and-off' nature and do not either happen or not happen (Holton, 2004). Therefore, it is difficult to predict risk variations because of the dynamic, uncertain nature of risk. Ward and Chapman (2003) suggest that the term risk needs to be replaced by uncertainty, as the latter is a neutral concept that reflects on present and future events having a multiplicity of possible outcomes involving diverse degrees of ambiguity and variability.

Many scholars, such as Perminova et al. (2008), Teece et al. (2016), and Ward and Chapman (2003) maintain that the uncertainty of an event has been logically embedded within the term risk. However, Perminova et al. (2008) highlighted that, in essence, the terms uncertainty and risk are dissimilar, and that uncertainty does not follow the risk formula. Uncertainty cannot be attached to probability, i.e., to the likelihood of occurrence of an event. The main difference is that uncertainty deals with both present and future events and describes uncertain situations, whereas risk deals only with future events that cannot be predicted. In general, uncertainty is an immeasurable element that cannot be foreseen; in other words, the likelihood of its occurrence cannot be estimated (Perminova et al., 2008; Teece et al., 2016; Ward and Chapman, 2003). This does not mean, however, that uncertainty cannot be managed.

International Journal of Management and Applied Research, 2021, Vol. 8, No. 4 
The terms uncertainty and risk are not comparable because of the intrinsic differences in their characteristics. Thus, there is no need to replace uncertainty management with risk management. For the purposes of this study, the term risk will be regarded as the possibility that something negative or positive, such as loss or gain, will happen.

\subsection{Risk Management Process}

A systematic process of orderly mitigation activities to reduce the probability of events with adverse effects or increase the likelihood of positive events is known as the risk management process (Olsson, 2007). This process is mainly designed with the aim of identifying and managing potential risks in order to diminish the disruption they may cause for the business.

Risk management is often seen as a process detached from management (Miller, 1992); however, the risk management process should always be tied to numerous management processes. Ideally, risk management is implemented at an early stage of any business operation, particularly in the beginning of the innovation life cycle (Bowers and Khorakian, 2014) or project life cycle (Ward and Chapman, 2003). The start-up phase or early stage of the innovation life cycle always entails a wide spectrum of uncertainties. Hence, if a company adopts even a simple risk management technique at the starting point of each phase, it is likely that foreseeable problems could be mitigated or avoided, and the management team would be able to monitor and control potential risks in a timely manner (Bowers and Khorakian, 2014). A rather comprehensive risk management process enables organisations to:

- Identify, analyse and prioritise risks

- Make informed decisions after thorough risk assessment

- Minimise the impact of threats and maximise the opportunities to enhance business performance

- Monitor operational processes and ensure adequate reporting

Such scholars as Bowers and Khorakian (2014), Teece et al. (2016), and Ward and Chapman (2003), as well as professional bodies (APM; PMI; and PRINCE2) all emphasise the importance of the following three core steps in risk management processes: risk identification, assessment and control. These core elements need to be better understood in terms of adapting risk management practice across the entire range of business operations.

\subsection{Risk Management Frameworks}

ISO 31000 (2018) defines risk management as "coordinated activities to direct and control an organization with regard to risk" and the purpose of a risk management framework is "to assist the organization in integrating risk management into significant activities and functions". Frameworks, such as the Orange Book (published by Her Majesty's Government in 2020) and the Risk Management Framework (United States federal government guidelines), aim to provide guidelines on making risk management more effective. Large firms are more likely to base their risk management processes on international standards like the International Standard for Risk Management (ISO 31000, 2018). However, each company may have its own

International Journal of Management and Applied Research, 2021, Vol. 8, No. 4 
unique approach to implementing the risk management process, because each firm has its own objectives, organisational structure, company policies, and managerial practices. Before attempting to embed a risk management framework, management must ensure that they understand the complexity of the external and internal business context, which is crucial to risk assessment and resource allocation (Bowers and Khorakian, 2014).

\subsection{Characteristics of Business Strategies}

The field of business strategy has evolved considerably in the past decades. Firms have mastered the art of analysing their competitive environment, defining their position, developing competitive and corporate advantages, and understanding threats in order to maintain their advantage over the challenges and threats posed by competition (Casadesus-Masanell and Ricart, 2010). Some diverse approaches that have evolved to enable more detailed strategising include: industrial organisation, the resource-based view, dynamic capabilities, and game theory. All these approaches help academics, business consultants and practitioners in the risk management field to understand the dynamics of competition and develop recommendations on how firms should formulate their competitive and corporate strategies.

Business strategy is ultimately about making decisions concerning plans and actions aimed at helping a firm to reach higher levels of competitiveness. Drucker (2001) sees decisionmaking as part of a process of innovation, including making the right decision at the right time in the right place. Porter $(1980 ; 1991 ; 1996)$ maintains that business strategy involves defining a firm's long-term position within the marketplace by making difficult trade-off decisions about what the firm will or will not do to provide value to its customers, while aiming at a superior return on investment.

When considering the dynamic relations between the enterprise and its competitors, it needs to be kept in mind that everything related to business strategy is ultimately about achieving or maintaining higher levels of competitive advantage (Ohmae, 1983). Hence, business strategy ensures coherence to the organisational level's decisions in order to attain the enterprise's goals. In other words, business strategy provides coherence and direction to the actions and decisions that an organisation makes, rather than offering a detailed and defined plan or programme of instructions.

Generally, business strategies that may lead an enterprise towards success have some common characteristics. One of these concern sits long-term and transparent goals. A long-term vision needs goals that are clear, straightforward and consistent over time (Gavinelli, 2016). This enables the enterprise to develop a sustainable and effective plan of action, as well as to have clear and measurable checkpoints during the implementation of the developed plan, unless changes are required.

In the case of changes, the ability of an enterprise to successfully and promptly recognise emerging opportunities and threats is grounded on a deep understanding of market trends, as well as on continuous monitoring of the business environment and the strategic behaviours of its direct and indirect competitors. An enterprise should

International Journal of Management and Applied Research, 2021, Vol. 8, No. 4 
objectively examine its resources and competences by identifying its strengths and weaknesses in order to adopt a long-term business strategy.

\subsection{Impact of Business Strategies on Risk Management}

The extent to which an enterprise can develop a position of superiority over its competitors is referred to as competitive advantage (Porter, 1980; 1991; 1996). Lowpriced products, superior quality services, short delivery time, state-of-the-art product features, all can contribute to competitive advantage. Competitive advantage does not remain constant throughout time. On the contrary, it is subject to market changes and intermittent resource constraints, especially in the fast-changing digital era. Regulatory changes, supply chain disruptions caused by the COVID-19 pandemic, better service offerings introduced by competitors, can all have a negative impact on an enterprise's competitive advantage.

There are various ways in which enterprises could turn risk into opportunity, and risk management can lead to enhancements of competitive advantage. Some scholars (Bowers and Khorakian, 2014; Chopra and Sodhi, 2014; Teece et al., 2016) have suggested that proactive risk management could help enterprises to gain and sustain competitive advantage.

Risks can be categorised in many different ways, according to the risk management literature. In this article, attention is paid to manageable risks that could be turned into competitive advantages. The first classification considers the possible advantages of the potential risks: that is, rewarded and unrewarded risks. Rewarded risks are risks that may add value to business, such as commercial risks when entering a new market or developing a new product. Enterprises should aim to identify potential challenges and formulate strategies on how to deal with them before taking rewarded risks like entering a new market. Unrewarded risks are those that have no potential return, and are typically imposed by external forces such as natural disasters, theft, pandemics, and workplace accidents. Every effort should be made to avoid, mitigate and reduce the damage caused by these events.

Risks can also be classified based on their impact on an enterprise; these can be broadly categorised as disruptive and non-disruptive risks. Disruptive risks are those that disrupt organisational activities, jeopardising its market position or ability to continue doing business. Non-disruptive risks, on the other hand, are those that firms face on a regular basis, such as demand fluctuations and supply delays. Although nondisruptive risk does not pose an immediate threat to an enterprise, the ability to deal effectively with the occurrence of a large number of these risks can have a significant impact on the organisation's performance and, as a result, on its competitive position.

While non-disruptive risks require enterprises to improve productivity to ensure cost efficiency, disruptive risks require enterprises to develop resilience, which could affect supply chain cost efficiency (Chopra and Sodhi, 2014). There are many riskmitigation strategies that can limit the impact of supply chain disruption and enhance cost efficiency. For instance, access to a well-connected supply chain network of suppliers, customers, and partners might provide early notice of a potential disruptive risk that could interfere with daily operational activities of an enterprise.

International Journal of Management and Applied Research, 2021, Vol. 8, No. 4 


\section{Methodology}

The qualitative approach was followed as the primary method of data collection, informed by the nature of the research objectives. Data were collected by means of semi-structured interviews guided by the non-probability purposive sampling method to obtain a sufficient sample of manufacturing and trading SMEs within the sports goods industry in Sialkot.

The selected sample, consisting of twenty SMEs, manufacturing and trading in the sports goods industry, has been obtained from the Sialkot Chamber of Commerce, which lists the names and contact details of more than 7,000 firms trading and manufacturing in the area. Respondents are generically marked and referred to as R1, $\mathrm{R} 2$, etc., up to R20. They represent key decision makers (owners, directors and managers) of the participating companies. The ratio between small and medium enterprises in the sample of the participating companies is $75 \%$ and $25 \%$. Therefore, the following discussion places emphasis on the small companies unless SMEs are mentioned explicitly.

Thematic analysis was adopted as the main method for analysing qualitative data to identify major themes in a specific body of literature and collected data (Cassell et al., 2021). Findings of this study are presented by the main themes, containing verbatim excerpts from interviews and their situational interpretation.

\section{Findings}

\subsection{Business Planning and Risk Management}

Due to limited resources and the nature of small businesses, executives do not always find a direct link between risk management and their business plans.

The implications of each identified category of risks need to be determined contextually. For that purpose, an understanding of the essence of the risk and its potential impact needs to be rationalised holistically, which will then lead the key decision makers to make changes in the business objectives pursued. Managing key categories of risks (financial risks, strategic risks, reputational risks and price fluctuation risks) is essential for the success of the business. It has implications for business strategy, structure and performance management.

According to Respondent R14, "If I want to increase the breadth of my product line, I need to do a market survey to find out if I can sell that specific product in the market". There is a perception that the success of the company is based on the introduction of new product lines, and that therefore managing the associated risks is vital. The respondent further said, "If I need to set up a new plant or install an additional unit, I survey the area and check viability of the new setup in the area before proceeding with implementation". It was noticed that there are common risks to analyse before expanding the business. If the risk analysis is done appropriately, then the chances of success are greater.

International Journal of Management and Applied Research, 2021, Vol. 8, No. 4 


\subsection{Tendencies in the Risk Management Process}

Identifying current and potential risks is crucial, as otherwise a company might not be able to deal with them without financial loss. Equally, not knowing risks in advance or neglecting them can put the company in a difficult situation.

Respondent R15 said, "We keep an eye on past risk-related events and try not to face the same risk again". In so saying, the respondent demonstrates awareness of heuristics in the risk management process. The respondent further added, "We continually check the old and emerging risks from time to time". While identification of new risks is important per se, the difficulty lies in the frequency of efforts to discover new risks. The respondent attested this by saying, "For example, if we get any problem in outsourcing, we change the vendor because we can lose customers due to low quality of the products".

Respondent R8, on the other hand, maintains that he does not have a clearly outlined process for identifying risks before they happen. According to him, the difficulty is not in identification of risks but in assessment of their potential impact. "We do not have an advanced setup for identifying risks; we do not know if the risk is severe before it happens". This approach significantly impedes risk mitigation, particularly in terms of timing.

Networking and news are significant sources of potential risk identification, which SMEs rely on heavily in their operations. Therefore, risk evaluation typically happens at once, instead of going through the stages of the risk management process, as this makes it possible to determine the risk's importance and prioritise a more effective mitigation. Additionally, it was noted that risks can be divided into two additional categories: risks related to customers and risks related to competitors (RespondentsR2, R4, R5, R6, R10, R15 and R16).

It was noticed that risk identification is affected by the capacity of small companies to mitigate particular risks. In other words, if some risks seem to be too difficult or even impossible to mitigate, then companies do not include them in their log of risks for further analysis (Respondents R1, R2, R3 and R7). This recalls the proverbial 'ostrich approach'.

With respect to the logged risks, small companies try to mitigate the most potentially damaging risks first. The prioritisation procedure appears to be perception driven, while grounded in the personal experience of decision makers (Respondents R8, R9, $\mathrm{R} 11, \mathrm{R} 12$, R13 and R14).

One of the most prominent concerns in the participating small companies is associated with the quality of their own goods. Hence it was almost unanimously voiced by respondents that risks associated with quality are the most observed ones. As Respondent R15 expressed it, "Quality control is our priority. By providing bad quality products, we can damage our reputation". However, the mitigation strategy for this type of risk is rather simplistic. "In the case of any problem with quality, we happily refund or change the purchased products". It was argued by some decision makers that this approach seeks to build buyers' trust for the sake of future contracts.

International Journal of Management and Applied Research, 2021, Vol. 8, No. 4 
Hence, the competitiveness of a small business is attributed to its flexibility in bending to the requests of corporate buyers, especially where the quality of produced goods is involved.

The second risks cluster comprises issues related to management of the labour force. The participating decision makers were convinced that treating and training employees well is essential for small companies, as risks associated with the labour force can escalate into quality and reputational risks that threaten the very existence of the company. However, a more typical approach reported by the respondents is downsizing when the company faces financial challenges.

In this context, Respondent R6 referred to the example of Saga Sports in Sialkot, the company famous for providing branded products for Nike. Saga Sports was ranked number 28th on Nike's list of suppliers. The company introduced the strategy of investing in their workers' wellbeing and skills, so that gradually Saga Sports climbed to the top of Nike's suppliers list. Respondent R6 added that "When you train the labourers, they can manage to mitigate almost half of the risks of the business". Hence, in order to be more competitive, the majority of small companies aim at the training and retention of their employees.

With regard to the frequency of risk assessment, it was noted that there is no specific time frame within which the risk assessment would be iteratively repeated. In fact, it was indicated by some decision makers that they deal with the most frequent risks as they arise (Respondents R1, R3, R6, R7 and R9). In terms of risk prioritisation, if a recurring risk is insignificant, the company may decide that such risks need to be addressed first, because otherwise the company often ends up spending most of its time, energy and resources on undoing the impact of those insignificant but numerous risks (Respondents R2, R4, R5, R8 and R10).

On the other hand, if there are any unknown risks that only emerge occasionally, the company may decide not to give these risks priority over the smaller ones, because solving them once they occur does not require that much energy or time. Risk management in action needs to be a continuous process, not a project that can be 'completed' and then forgotten. The business, its environment, and its risks are continually changing. So, this change process should be consistently and continually monitored. When respondents were asked whether they revisited risks that had arisen in the past, almost half answered positively; while the others said that they did not need to, or that they did not have the time to monitor the risks constantly. This fact indicates a need for a more formal framework coalescing into one strategic decision making and risk management scheme.

\section{Discussion}

The earlier explored relationship between risk management and business strategies in the sports goods industry in the city of Sialkot in Pakistan contained an emphasis on managing risks and their potential outcomes. In discussions with the participating decision makers, it became clear that they are ultimately concerned with risks in their businesses and their mitigation and elimination. But in essence, the mitigation most

International Journal of Management and Applied Research, 2021, Vol. 8, No. 4 
likely than not rests on action plans in search of a suitable competitive strategy for achieving the anticipated outcomes. This line of thinking led to a need to redirect the decision makers' reflections towards a better way forward in the highly competitive situation of the sports goods industry, arriving at a schematic representation that consolidates strategies, risks and outcomes (Figure 1).

In the contemporary highly competitive and globalised world, achieving and sustaining competitive advantage by small companies is more difficult than ever. It appears that the pursuit of higher profitability while lowering or at least promptly addressing the main categories of risk is possible by focusing on the development of transient competitive advantages (McGrath, 2013). This notion of transient advantage rests on a mindset to be adopted by key decision makers in small companies who need to learn to formulate new strategic initiatives again and again by assessing the current and emerging risks faced by businesses.

Figure 1 Relationship between strategies, risks and outcomes

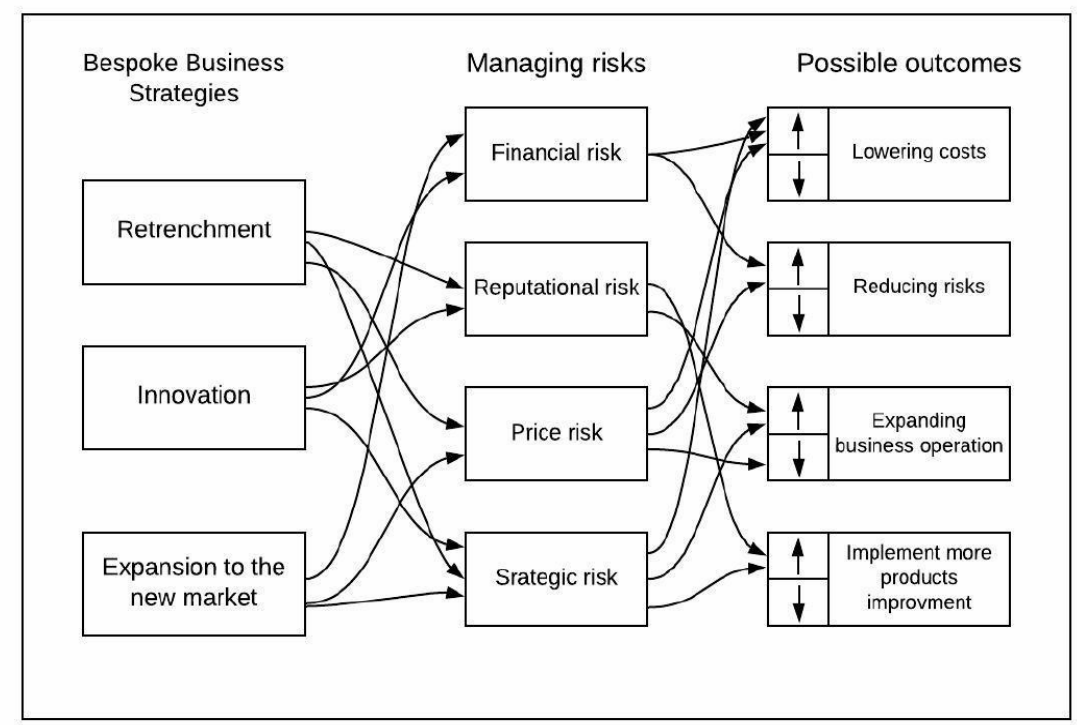

\subsection{Retrenchment Strategy}

Retrenchment strategy refers to a reduction in assets and costs, especially through reduction in assets and inventory as well as reduction in the number of employees (Lim et al., 2020; Morrow et al., 2004; Rico et al., 2021). It aims to mitigate the reputational, price fluctuation and strategic risks, as well as that of insolvency.

The current study found that, in a situation of financial difficulty, some small companies try to survive by reducing the workforce, which may have negative consequences, e.g., a decline in productivity and motivation amongst the remaining workers. Moreover, these workers have to carry an extra workload to keep up with production targets. In a study of retrenchment strategy used by SMEs, Rico et al. (2021) found that retrenchment of employees and assets is often associated with liquidation. Rico et al. (2021) added that neither intangible assets nor tangible assets retrenchment is associated with firm survival. 
The possible outcome in this scenario is double-edged. On the one hand, companies can achieve cost savings and subsequent enhanced profitability. On the other hand, workforce morale and potential productivity may suffer, resulting in lower performance and high turnover of employees seeking more stable employment. Altogether, the result may be an increase in reputational risk for companies, although, if they are aware of the consequences of this specific business strategy, such awareness could act as risk mitigation. SMEs need to be cautious not to over-retrench when facing financial difficulty.

This research supports the findings of previous studies which remarked that business owners and executive managers should focus on improving operations and immediate liquidity to avoid liquidation or bankruptcy (Lim et al., 2020; Morrow et al., 2004; Rico et al., 2021). Instead of reducing the workforce or selling assets, SMEs in financial distress should seek turnaround strategies that offer alternatives, through firm survival, to creditors claiming repayment (Rico et al., 2021).

\subsection{Innovation Strategy}

Innovation strategy is an aggregate name for various long-term approaches considering innovation as an integral element of forthcoming changes. According to Dervitsiotis (2010), the key feature of such a strategy is reliance on a pipeline of innovations in a business rather than aiming at one specific innovation.

Sajdak (2015) found that an agile enterprise which has the capability to innovate and respond in a timely manner to market changes is more likely to thrive in a competitive business environment. While innovativeness is a central criterion of "agility" and "acuity" in firms (Sajdak, 2015), it entails commercial risk, especially for SMEs, due to the uncertainties inherent in the market's acceptance of innovations (Teece et al., 2016).

It has been found that, through the use of manual stitching or other hand-working methods, most of the smaller companies cannot provide large quantities of products in a short period of time. This may trigger higher financial and reputational risks, since to compete effectively and provide larger quantities of products of sufficient quality in less time, small companies need to install new and often computerised machinery which can increase their productivity.

To install such new automation, the companies need to invest more in their manufacturing setup, which puts them under significant financial pressure. Mitigating this kind of financial risk is usually possible via the sale of unnecessary assets or a loan from the bank, which, however, puts a strain on the amount of a small firm's working capital.

It has been noted that sufficient automation can generate superior quality of products in larger batches, along with the benefits of low labour unit cost, increased productivity, and short lead time (Andreff and Andreff, 2009). However, this study found that most SMEs face financial and technical challenges in relation to upgrading their manufacturing processes and investing in research and development, as well as introducing automation that could facilitate an increase in their productivity.

International Journal of Management and Applied Research, 2021, Vol. 8, No. 4 


\subsection{Expansion to New Markets}

Expansion to new markets as a strategy is associated with growth strategies and is often based on the foundational work of Ansoff $(1957$; 1984). The first phase of this strategy emphasises market development as a way of entering new markets using existing products. This study found that in situations of frequent price fluctuations, a small company can quickly change its business strategy and adopt a more competitive stance of selling niche products and meeting the demand globally in small quantities at better prices.

These findings are in line with previous empirical studies on niche markets (Liao et al., 2021) and international trade specialisation (Andreff and Andreff, 2009). Marketing plays an important role by communicating product attributes to the niche market audience (Ansoff, 1984; Liao et al., 2021; Parrish et al., 2006). Parrish et al. (2006) suggested that targeting consumers is the most important factor, as understanding them thoroughly enables the company to embark on the sale of niche products. However, adopting the strategy of expanding marketing operations in the current market by offering unique products can lead to as yet unknown risks.

\section{Conclusions}

The main purpose of this study was to explore the extent to which the chosen competitive strategy would enable a small firm in the sports goods industry in Sialkot to have a better fit with the business environment in the context of managing risks. Certain dependencies between bespoke competitive strategies and risks were identified and visualised in the shape of a causal framework (Figure 1), providing visual support to decision makers in small firms within the sports goods industry.

This study has also found that small companies have considerable deficits in formal methods of risk management. The research interviews with key decision makers revealed that they often cannot determine their overall risk positioning empirically. Hence, managing directors more often than not find themselves in the position of identifying key risks perceptually without the use of any theoretical methods.

The sports goods industry in Sialkot is hypercompetitive; that is, characterised by the presence of a large number of local as well as international competitors who are able to respond quickly to fluctuating market trends. In such a situation it is not possible for one company to keep a competitive advantage for a long time. Therefore, the three most viable competitive strategies (retrenchment, innovation, and expansion to new markets) have been explored as a way of formulating a portfolio of transient advantages for small companies, instead of aiming to develop a suitable competitive advantage.

The developed causal framework provides practical help for key decision makers in determining an appropriate competitive strategy that would enable firms to evaluate risks and their potential consequences prior to committing to specific action plans. This would enable small companies to be more competitive by streamlining their

International Journal of Management and Applied Research, 2021, Vol. 8, No. 4 
internal processes, including risk mitigation approaches, in seeking to achieve higher levels of profitability.

Further research can progress in the direction of providing key decision makers, particularly in smaller companies, with theoretical guidelines developed specifically for companies facing serious financial, labour and/or technology limitations when operating in highly competitive and turbulent business environments. In essence, these guidelines can be industry specific or even span industry borders when it comes to specific transformational activities, such as manufacturing.

\section{References}

1. Andreff, M. and Andreff, W. (2009), "Global Trade in Sports Goods: International Specialisation of Major Trading Countries", European Sport Management Quarterly, Vol. 9, No. 3, pp. 259-294. https://doi.org/10.1080/16184740903024029

2. Ansoff, H. I. (1957), "Strategies for Diversification", Harvard Business Review, Vol. 35, No. 5, pp.13-124.

3. Ansoff, H. I. (1984), Implanting Strategic Management, New York: Prentice Hall.

4. Association of Project Management (APM) (2021), What is risk management? [Online] Available from:https://www.apm.org.uk/resources/what-is-projectmanagement/what-is-risk-management/ [Accessed on 2 October 2021].

5. Awan, H.M. and Ishaq Bhatti, M. (2003), "An Evaluation of ISO 9000 Registration Practices: ACase Study of Sports Goods Industry", Managerial Finance, Vol. 29, No. $\quad$ 7, pp. https://doi.org/10.1108/03074350310768373

6. Awan, U., Khattak A. and Kraslawski A. (2019), "Corporate Social Responsibility (CSR) Priorities in the Small and Medium Enterprises (SMEs) of the Industrial Sector of Sialkot, Pakistan". In: Golinska-Dawson P., Spychała M. (eds) Corporate Social Responsibility in the Manufacturing and Services Sectors. EcoProduction (Environmental Issues in Logistics and Manufacturing). Berlin: Springer. https://doi.org/10.1007/978-3-642-33851-9_15

7. Bowers, J. and Khorakian, A. (2014), "Integrating Risk Management in the Innovation Project", European Journal of Innovation Management, Vol. 17, No. 1, pp. 25-40. https://doi.org/10.1108/EJIM-01-2013-0010

8. Casadesus-Masanell, R. and Ricart, J. E. (2010), "From Strategy to Business Models and to Tactics", LongRange Planning, Vol. 43, No. 2-3, pp. 195-215. https://doi.org/10.1016/j.lrp.2010.01.004

International Journal of Management and Applied Research, 2021, Vol. 8, No. 4 
9. Cassell, C.; Cunliffe, A. L. and Grandy, G. (2021), The SAGE Handbook of Qualitative Business and Management Research Methods, UK: Sage Publisher. /https://doi.org 10.4135/9781526430212

10. Chopra, S. and Sodhi, M. S. (2014), "Reducing the Risk of Supply Chain Disruptions", MIT Sloan Management Review, Vol. 55, No. 3, pp. 72-80.

11. Dervitsiotis, K. N. (2010), “A Framework for the Assessment of an Organisation's Innovation Excellence", Total Quality Management \& Business Excellence, Vol. 21, No. 9, pp. 903-918.https://doi.org/10.1080/14783363.2010.487702

12. Drucker, P. F. (2001), The Essential Drucker, New York: Harper and Brothers.

13. Gavinelli, L. (2016), Business Strategies and Competitiveness in Times of Crisis: A Survey on Italian SMEs, London: Palgrave Macmillan. https://doi.org/10.1057/978-1-137-57810-5

14. Her Majesty's Government (2020), The Orange Book: Management of RiskPrinciples and Concepts, UK: HM Government.

15. Holton, G. A. (2004), "Defining Risk", Financial Analysts Journal, Vol. 60, No. 6, pp. 19-25. https://doi.org/10.2469/faj.v60.n6.2669

16. International Organisation for Standardisation (ISO) (2018), ISO31000: 2018 Risk Management-Guidelines. Sydney: ISO.

17. Liao, S. H.; Widowati, R. and Yang, K. C. (2021), "Investigating Sports Behaviors and Market in Taiwan for Sports Leisure and Entertainment Marketing Online Recommendations", Entertainment Computing, Vol. 39, 100442. https://doi.org/10.1016/j.entcom.2021.100442

18. Lim, D. S.; Morse, E. A. and Yu, N. (2020),"The Impact of the Global Crisis on the Growth of SMEs: A Resource System Perspective",International Small Business Journal, Vol. 38, No. 6, pp. 492-503. https://doi.org/10.1177/0266242620950159

19. Lund-Thomsen, P.(2013), "Labor Agency in the Football Manufacturing Industry of Sialkot, Pakistan", Geoforum, Vol. 44, pp. 71-81. https://doi.org/10.1016/j.geoforum.2012.04.007

20. McGrath, R. G. (2013) "Transient Advantage", Harvard Business Review, Vol. 91, No. 6, pp. 61-70.

21. Miller, K. A. (1992), "Framework for Integrated Risk Management in International Business", Journal of International Business Studies, Vol. 23, pp. 311331.https://doi.org/10.1057/palgrave.jibs. 8490270

International Journal of Management and Applied Research, 2021, Vol. 8, No. 4 
22. Morrow, J.L.; Johnson, R.A. and Busenitz, L.W.(2004), "The Effects of Cost and Asset Retrenchment on Firm Performance: The Overlooked Role of a Firm's Competitive Environment", Journal of Management, Vol. 30, No. 2, pp. 189208.https://doi.org/10.1016/j.jm.2003.01.002

23. National Institute of Standards and Technology (2021), NIST Risk Management Framework, available from: https://csrc.nist.gov/projects/risk-management/about$\underline{\mathrm{rmf}}$ [Accessed on 2 October 2021].

24. Ohmae, K. (1983), The Mind of the Strategist: Business Planning for Competitive Advantage, the Art of Japanese Business, New York: Penguin Books.

25. Olsson, R. (2007), "In Search of Opportunity Management: Is the Risk Management Process Enough?", International Journal of Project Management, Vol. 25, No. 8, pp. 745-752. https://doi.org/10.1016/j.ijproman.2007.03.005

26. Parrish, E. D.; Cassill, N. L. and Oxenham, W.(2006), "Niche Market Strategy for a Mature Marketplace", Marketing Intelligence and Planning, Vol. 24, No. 7, pp. 694-707. https://doi.org/10.1108/02634500610711860

27. Perminova, O.; Gustafsson, M. and Wikström, K. (2008),"Defining Uncertainty in Projects - a New Perspective", International Journal of Project Management, Vol. 26, No. 1, pp. 73-79.https://doi.org/10.1016/j.ijproman.2007.08.005

28. PRINCE2 (2021), PRINCE2 Wiki: Risk, [Online] available from: https://prince2.wiki/theme/risk/ [Accessed on 2 October 2021].

29. Porter, M. E. (1980), Competitive Strategy: Techniques for Analyzing Industries and Competitors,New York: Free Press.

30. Porter, M.E. (1991), "Towards a Dynamic Theory of Strategy", Strategic Management Journal, Vol. 12, No. S2, pp. 95-117. https://doi.org/10.1002/smj.4250121008

31. Porter, M. E. (1996),"What is strategy?", Harvard Business Review, Vol. 74, No. 6, pp. 61-78.

32. Project Management Institute (PMI) (2019), The Standard for Risk Management in Portfolios, Programs, and Projects, Pennsylvania: PMI.

33. Rico, M.; Pandit, N.R. and Puig, F. (2021), "SME Insolvency, Bankruptcy, and Survival: An Examination of Retrenchment Strategies", Small Business Economics, Vol. 57, pp. 111-126. https://doi.org/10.1007/s11187-019-00293-z

34. Sajdak, M. (2015), "Theoretical and Practical Aspects of Developing Agile Enterprises", International Journal of Management and Applied Research, Vol. 2, No. 4, pp. 144-155. https://doi.org/10.18646/2056.24.15-015

International Journal of Management and Applied Research, 2021, Vol. 8, No. 4 
35. Small and Medium Enterprises Development Authority (SMEDA) (2021), Sports Goods Sector Brief, available from: https://smeda.org/index.php?option $=$ com phocadownload\&view $=$ category\&down load=1752: sports-goods-2021\&id=28:sectoral-briefs \&Itemid=139 [Accessed on 2 October 2021].

36. Teece, D.; Peteraf, M. and Leih, S. (2016), "Dynamic Capabilities and Organizational Agility: Risk, Uncertainty, and Strategy in the Innovation Economy", California Management Review, Vol. 58, No. 4, pp. 13-35. https://doi.org/10.1525/cmr.2016.58.4.13

37. Ward, S. and Chapman, C. (2003), "Transforming Project Risk management into Project Uncertainty Management", International Journal of Project Management, Vol. 21, No. 2, pp. 97-105. https://doi.org/10.1016/S0263-7863(01)00080-1 